6 Granerus G, Aurell M. Reference values for Cr-EDTA clearance as a measure of glomerular filtration rate. Scand f Clin Lab Invest 1981;41:611-6.

7 Ikeda I, Iinuma K, Takai M, Yanagawa Y, Kurata K, Oginara T. Measurement of plasma renin activity by a simple solid phase radioimmunoassay. f Clin Endocrinol Metab 1981;54:423-8.

8 Kappelgaard AM, Damkjær Nielsen M, Giese J. Measurement of angiotensin II in human plasma: technical modifications and practical experience. Clin Chim Acta 1976;10:299-306.

9 Neels HM, Scharpé SL, van Sande ME, Verkerk RM, van Anker KJ. Improved micromethod for assay of serum angiotensin-converting enzyme. Clin Chem 1982;28:1352-5.

10 Nordén G, Granerus G, Nyberg G. Diabetic cystopathy-a risk factor in diabetic nephropathy? $\mathcal{F}$ Diabetic Complications 1988;2:203-6.

11 Nyberg G, Nordén G, Attman PO, Aurell M, Uddebom G, Arvidsson R, et al. Diabetic nephropathy: is dietary protein harmful? $\mathrm{f}$ Diabetic Complications 1987;1:37-40.

12 Parving HH, Hommel E, Smidt UM. Protection of kidney function and decrease in albuminuria by captopril in insulin dependent diabetics with nephropathy. BMF 1988;297:1086-91.

13 Parving HH, Hommel E, Damkjær Nielsen M, Giese J. Effect of captopril on blood pressure and kidney function in normotensive insulin dependent diabetics with nephropathy. $B M \mathcal{F}$ 1989;299:533-6.

14 Cheng IK, Ma JT, Chan MK. Comparison of captopril and enalapril in the treatment of hypertension in patients with non-insulin dependent diabetes mellitus and nephropathy. Int Urol Nephrol 1990;22:295-303.

15 Bilo HJ, Westerman RF, Nicolaas-Merkus AM, Donker AJ. Effects of enalapril with and without hydrochlorothiazide in hypertensive patients with non-insulin dependent diabetes mellitus. Diabetes Res 1988;9:21-5.

16 Zeller K, Whittaker E, Sullivan L, Raskin P, Jacobson HR. Effect of restricting dietary protein on the progression of renal failure in patients with insulin-dependent diabetes mellitus. N Engl f Med 1991;324:78-84.

17 Mogensen CE. Long term antihypertensive treatment inhibiting progression of diabetic nephropathy. $B M 7$ 1982;285:685-8.

18 Christensen CK, Mogensen CE. Effect of antihypertensive treatment on progression of incipient diabetic nephropathy. Hypertension 1985;7:9-13.
9 Hommel E, Mathiesen E, Edsberg B, Bahnsen M, Parving HH. Acute reduction of arterial blood pressure reduces urinary albumin excretion in type 1 (insulin dependent) diabetic patients with incipient nephropathy. Diabetologia 1986;29:211-5.

20 Björck S, Herlitz H, Nyberg G, Granerus G, Aurell M. Effect of captopril on renal hemodynamics in the treatment of resistant renal hypertension. Hypertension 1983;5(suppl 3): 152-3.

21 Sandahl Christiansen J. On the pathogenesis of the increased glomerula filtration rate in short-term insulin-dependent diabetes. Dan Med Bull 1984;31:349-61.

22 Yoshida Y, Kawamura T, Ikoma M, Fogo A, Ichikawa I. Effect of antihypertensive drugs on glomerular morphology. Kidney Int 1989;36: 626-35.

23 Keane WF, Raij L. Relationship among altered glomerular barrier permselectivity, angiotensin II and mesangial uptake of macromolecules. Lab Invest 1985;52:599-604.

24 Herlitz H, Tarkowski A, Svalander C, Volkman R, Westberg G. Beneficial effect of captopril on systemic lupus erythematosus-like disease in lpr/lp mice. Int Arch Allergy Appl Immunol 1988;85:272-7.

25 Mulec H, Johnsen S-A, Björck S. Relation between serum cholesterol an diabetic nephropathy. Lancet 1990;335:1537-8.

26 Keane WF, Kasiske BL, O'Donell MP. Hyperlipidemia and the progression of renal disease. Am f Clin Nutr 1988;47:157-60.

27 Kasiske BL, O'Donnell PM, Schmitz PG, Kim Y, Keane WF. Renal iniury of diet-induced hypercholesterolemia in rats. Kidney Int 1990;37:880-91.

28 Heeg JE, De Jong PE, van der Hem GK, de Zeeuw D. Efficacy and variability of the antiproteinuric effect of ACE inhibition by lisinopril. Kidney Int 1989;26:272-9.

29 Parving HH, Hommel E. Prognosis in diabetic nephropathy. BMf 1989;299. 230-3.

30 Kamper A-L, Juul-Nielsen O. Effect of enalapril on hemoglobin and serum erythropoietin in chronic nephropathy. Scand $\mathcal{Y}$ Clin Lab Invest 1990;50: 611-8.

(Accepted 18 October 1991)
Department of Pediatrics, McMaster University, Hamilton, Ontario, Canada R K Whyte, FRCPC, associate professor

Correspondence to: Department of Neonatal Pediatrics, Grace Maternity Hospital, Halifax, Nova Scotia, Canada B3H 1W3.

BMf 1992;304:343-6

\title{
First day neonatal mortality since 1935: re-examination of the Cross hypothesis
}

\author{
R K Whyte
}

Abstract

Objectives-To describe the change in first day infant mortality during 1935-87. To examine the hypothesis that excess first day mortality in the 1950 s and 1960 s was attributable to restricting oxygen for sick newborn infants.

Design-Time series analysis of first day infant mortality and stillbirth rates.

Setting-England and Wales and the United States of America.

Subjects-All first day infant deaths, all neonatal deaths, and all stillbirths.

Main outcome measures-Rate of fall in mortality, dates of deviation of mortality from established fall, and correlation with stillbirths.

Results - In England and Wales first day infant mortality fell by 3.1\% a year, except between 1951 (95\% confidence interval 1951 to 1954 ) and 1980 (confidence interval $<1$ year). During these years there were 37000 excess deaths. In the United States an annual fall of $2.7 \%$ was interrupted in 1955 (1951 to 1954 ) and resumed in 1980 (1978 to 1980), resulting in 195000 excess deaths. A similar pattern was observed in stillbirth rates.

Conclusions-Restriction of oxygen in sick newborn infants cannot be the sole cause of the interruption in fall of first day neonatal mortality as stillbirth rates were also affected. The timing of onset and the course of the deviation is not consistent with the oxygen restriction hypothesis. Further investigation is needed to identify a factor affecting both fetal and newborn survival between 1950 and 1980.

\section{Introduction}

In 1973 Cross reported first day mortality in England and Wales and the United States for 1935-71. ${ }^{1}$ In both American and British populations first day mortality fell during 1935 to 1950 . He described "an abrupt hold up" in the steady rate of fall around 1950 in England and Wales, and a "very distinct hump in the curve of mortality" from 1954 in the United States. This pattern was not seen in death rates of infants dying between 1 and 6 days of age. The interruption in the fall occurred only in low birthweight infants and was more noticeable in infants born in urban centres. ${ }^{2}$

Cross hypothesised that the reversal of the previous improvement in mortality was attributable to oxygen restriction. This had become normal practice in neonatal care after the discovery that excessive ambient oxygen was a cause of retrolental fibroplasia. ${ }^{34} \mathrm{He}$ calculated that for every infant saved from blindness 16 died of hypoxia. Later the oxygen restriction hypothesis was generally cited as evidence of the fatal effects of hypoxia in the newborn. ${ }^{5-8}$

Data on neonatal mortality are now available up to 1987. I examined the data to determine the characteristics of the disturbance in reduction of first day infant mortality, to determine its contribution to neonatal death, and to re-examine the oxygen restriction hypothesis.

\section{Methods}

I examined statistics for England and Wales ${ }^{9.15}$ and for the United States ${ }^{16-18}$ for the 53 years from 1935 to 1987. The definition of fetal death in England and Wales included fetuses up to 28 weeks' gestation, whereas in the United States it applied to a fetus before 20 weeks' gestation. ${ }^{19} \mathrm{~A}$ neonatal death was defined as the death before 28 days of age of a liveborn infant born beyond these gestational age limits. Stillbirths were defined by the same lower limits of gestational age. Neonatal mortality was expressed as deaths per thousand live births and stillbirth rates as deaths per thousand total births.

The data seemed to describe a disturbance of an established exponential rate of fall in first day infant mortality. They were therefore analysed after 
logarithmic transformation with a linear regression model with appropriate correction for autocorrelation as described for a time series. ${ }^{20-22}$ From this model the most likely dates of change in the fall in mortality with $95 \%$ confidence intervals were determined ${ }^{23}$ and rates of fall and excess mortality attributable to the disturbance were estimated.

\section{Results}

First day mortality fell exponentially in both populations from 1935 to 1950 and from 1980 to 1987 (fig 1) The best estimate of the dates defining the interruption of the fall is 1951 to 1980 for England and Wales and 1955 to 1979 for the United States. Both before and after the interruption the first day neonatal mortality fell by $3 \cdot 1 \%$ annually in England and Wales and by $2.7 \%$ in the United States. After 1951 in England and Wales mortality increased, reaching a maximum deviation from the previous exponential fall in 1967 (fig 2 (top)). First day mortality then fell very rapidly until 1980, when the rate of fall returned to that seen before 1950 . The same general pattern occurred in the United States, where mortality started increasing in 1955 , reached a maximum deviation from the previous exponential fall in 1966, and then fell increasingly quickly until resuming in 1979 the slope described before the disturbance (fig 3 (top)).

Both data sets conformed closely to a regression model described by an exponential fall in baseline first day mortality. Superimposed on this is a deviation which is closely defined by a quadratic function. The 95\% confidence intervals for the first deviant year were 1951 to 1954 for England and Wales and 1953 to 1955 for the United States. For the final deviant years the confidence limit included only one year (1980) for England and Wales and the years 1978 to 1980 for the United States. The equations describing rate of fall before and after the disturbance were found to be coincident $(p>0 \cdot 13)$, indicating that once the disturbance was over the rate of fall continued as if it had been uninterrupted.

Neonatal mortality (infants aged 0-28 days) and stillbirth rates showed a similar pattern to the first day neonatal mortality (figs 2 and 3). Stillbirth rates were highly correlated with first day mortality, even after accounting for the correlation with year (partial correlation coefficients $(r)$ were $\mathbf{0 . 9 3}$ for England and Wales and $\mathbf{0 . 8 5}$ for the United States).

Excess mortality can be roughly estimated by determining the deviation of annual mortality from the values predicted from the conforming years. Multiplied by total live births, the deviation gives an annual

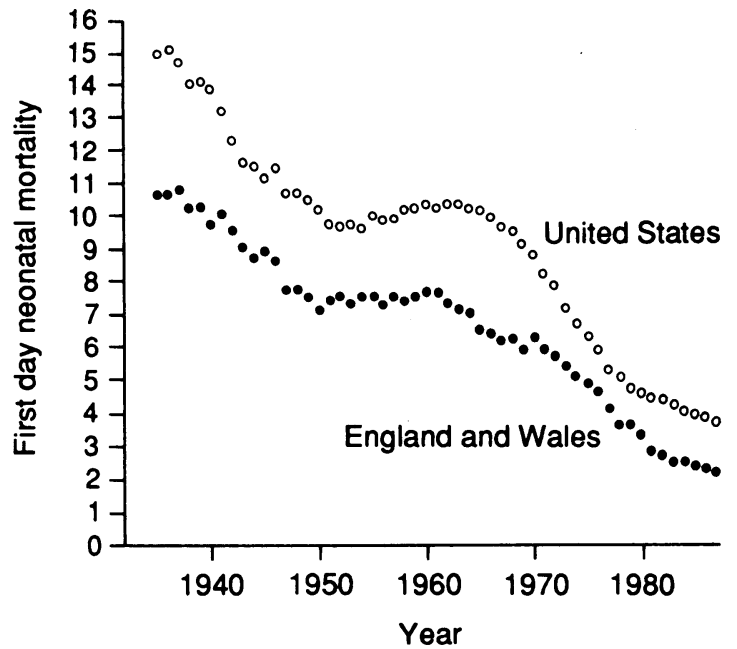

FIG 1-First day neonatal mortality (deaths/1000 live births) for England and Wales and the United States by calendar year
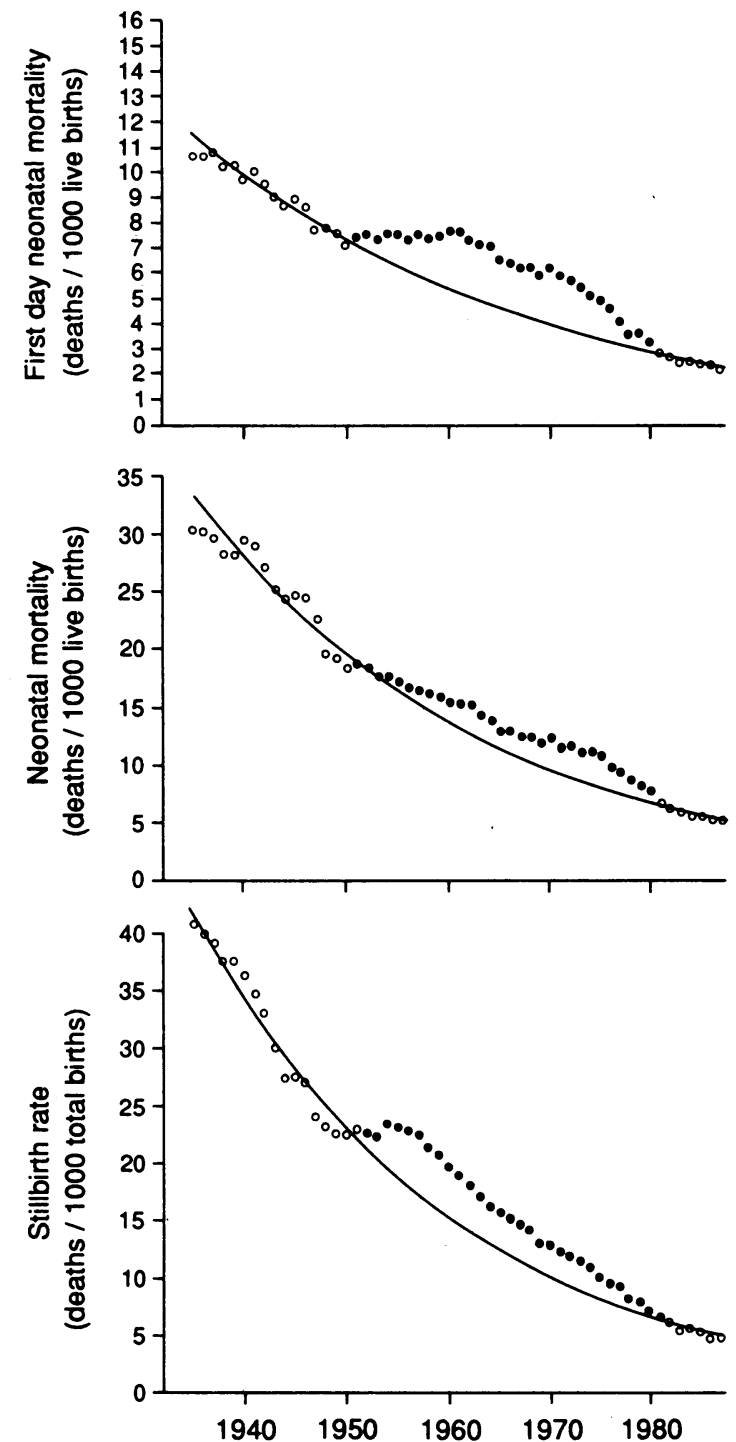

FIG 2-First day mortality neonatal (0-28 days) mortality, and stillbirth rates for England and Wales. Lines of best fit are interpolated from the data for conforming years 1935-50 and 1981-7. Solid circles correspond to deviant years

value of the excess deaths attributable to the interruption in improvement in mortality seen in the deviant years. In England and Wales there were 37000 excess first day deaths, nearly all of the $\mathbf{4 0 0 0 0}$ excess total neonatal deaths. These excess first day deaths averaged 1200 a year and accounted for $12 \%$ of all neonatal deaths from 1951 to 1980 . In the United States there were 195000 excess first day deaths, contributing to 280000 excess total neonatal deaths, representing 8000 deaths a year or $13 \%$ of neonatal deaths from 1955 to 1978 . The numbers of excess deaths must be multiplied manyfold to include the world population of all infants who died from similar effects.

\section{Discussion}

Analysis of the first day mortality statistics for England and Wales and the United States for the years 1935-87 shows that a consistent rate of fall in first day mortality in the first $15-20$ years was interrupted in 1951 (95\% confidence interval 1951 to 1954) in England and Wales and in 1955 (1953 to 1955) in the United States. Mortality then increased for about 10 years but was counteracted almost immediately by an opposite "correcting" influence until mortality had fallen to its expected value had the rate of fall to 1951 not been interrupted. Once the interruption was corrected the fall in mortality resumed its earlier rate. The distur- 
bance left no residual effect, suggesting that the "correcting" influence was a function of the "interrupting" influence. The model suggests a modified single cause with discrete onset and extinction.

The difference in definition of neonatal death in England and Wales and the United States partly explains the lower first day mortality in England and Wales. The mortality in the two populations has not been compared. The confidence intervals around the dates identifying the start and end of the disturbance in the fall in mortality indicate that these dates are indistinguishable between the American and British populations.

Cross, ${ }^{1}$ and later Bolton and Cross, ${ }^{2}$ described first day neonatal mortality from 1935 to 1971 and suggested that the interruption in the fall in mortality was due to oxygen restriction in neonatal care. My analysis of data up to 1987 makes the oxygen restriction hypothesis untenable or incomplete. The period during which oxygen restriction was common practice has never been defined, although Cross describes the paper by Ashton et al in $1953^{24}$ as "the final proof" that high arterial oxygen tension caused retrolental fibroplasia and 1957 to 1965 as the period in which incubators were modified to limit oxygen to less than $40 \%$. For an experimental finding to be communicated, converted into clinical policy, disseminated, and translated into an effect on annual mortality must take some years. The paper by Ashton et al is too late to account for the interruption in the fall in mortality in England and
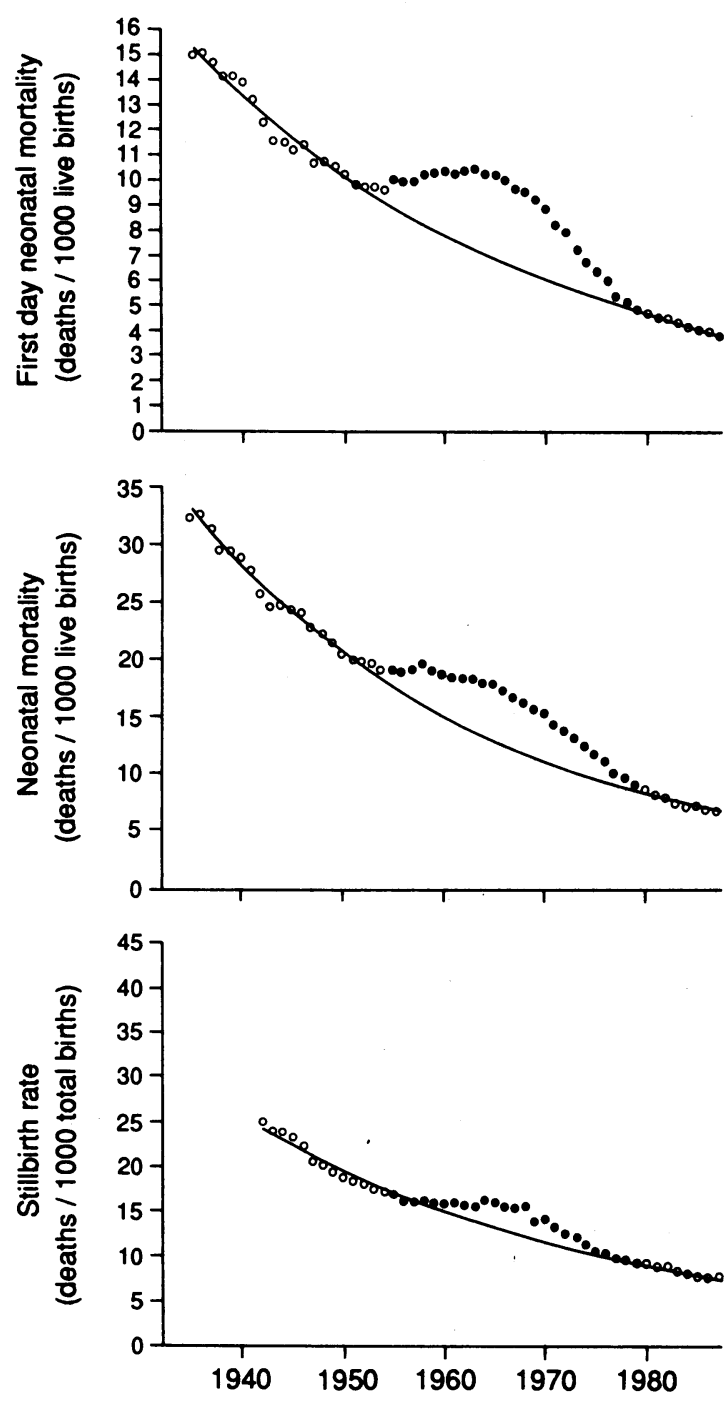

FIG 3-First day mortality, neonatal (0-28 days) mortality, and stillbirth rates for the United States. Lines of best fit are interpolated from the data conforming years 1935-64 and 1980-7. Solid circles correspond to deviant years
Wales. ${ }^{25-27}$ In the United States conflicting reports about the role of oxygen in retrolental fibroplasia and infant mortality were published during $1949-54 . .^{628}$ State recommendations to restrict oxygen were announced between 1954 and $1958 .{ }^{\circ}$ It is not possible to determine whether clinicians responded to or anticipated these guidelines, but clearly the rise in infant mortality was well established before most of these announcements were made.

The disturbance in the fall in neonatal mortality is striking in its symmetry. This suggests a single causal factor rather than a multifactorial cause. The clinical protocols which replaced oxygen restrictive policies were not simple reversals of policy: they were new and complex forms of management. ${ }^{29}$ The recovery of the earlier trends in infant mortality would be expected to be a more attenuated process than the original deviation.

The rise in stillbirth rate is closely correlated with first day mortality, and this cannot be explained by the oxygen restriction hypothesis. The correlation with stillbirth rate has been noted before ${ }^{30}$ and excludes mechanisms which affect neonatal care alone, such as inadequate resuscitation ${ }^{26}$ or untested procedures in neonatal care. ${ }^{25}$ The disturbances in the fall in infant mortality are not due to a transfer or reclassification of deaths from later neonatal mortality as the data for all neonatal deaths from 0 to 28 days show the same disturbance.

\section{ALTERNATIVE EXPLANATIONS}

It is difficult to identify a change in reporting practice which could result in this disturbance in neonatal mortality. Although there were some modifications of the definition of stillbirth in the earlier years, ${ }^{19}$ these had little effect and all moved towards including fetuses of earlier gestation or lower body weight in the definition of stillbirth. While such practices might cause an apparent rise in the stillbirth rate, they would not result in a subsequent readjustment to the earlier established rate of fall. The data are adjusted for birth rate, and in any case the rise in birth rate after the war had passed its zenith before the disturbance in mortality had reached its maximum. ${ }^{916}$

These observations indicate a common maternalfetal cause such as an economic or environmental factor. As the period from 1950 to 1980 extends from postwar economic depression into recovery, wealth, and recession there are no clear economic correlates, but these should be pursued in detail. No universal change in nutritional management of pregnant women is apparent ${ }^{31}$ but pharmacological and nutritional management practices should be carefully re-examined.

Among environmental factors is the rise in exposure to strontium- 90 resulting from atmospheric weapons testing, which has been closely correlated, both geographically and temporarily, with excess fetal and infant deaths from 1950 to $1964 .{ }^{32} \mathrm{~A}$ rise in early infant mortality in southern Germany has accompanied the increase in exposure to radioisotopes resulting from the Chernobyl nuclear reactor explosion in $1986 .{ }^{33}$ Future characteristics of fetal and infant mortality in this country will help to determine the effects of such exposure. This and other hypotheses should be developed and tested to determine the cause of this important loss of life.

I am grateful to Dr J F MacGregor, Dr C H Goldsmith, Dr J Hurley, and Ms R Labelle of McMaster University for advice on data analysis. Drs J C Sinclair, W A Silverman, and G R Norman provided expert commentary on the manuscript and encouragement.

1 Cross KW. Cost of preventing retrolental fibroplasia? Lancet 1973;ii:954-6.

2 Bolton DPG, Cross KW. Further observations on the cost of preventing retrolental fibroplasia. Lancet 1974;i:445-8. 
3 Kinsey VE. Retrolental fibroplasia. Cooperative study of retrolental fibroplasia and the use of oxygen. AMA Arch Ophthalmol 1956;56:481-543.

4 Silverman WA. The national cooperative study. Retrolental fibroplasia: a modern parable. Toronto: Grune and Stratton, 1980:37-42.

5 Silverman WA. The consequences of oxygen restriction. Retrolental fibroplasia: a modern parable. Toronto: Grune and Stratton, 1980:53-8.

6 American Academy of Pediatrics Committee on Fetus and Newborn. History of oxygen therapy and retrolental fibroplasia. Pediatrics 1976;57 (suppl):

7 Hack M, Fanaroff AA. Outcomes of extremely-low-birth-weight infants between 1982 and 1988. N Engl f Med 1989;321:1642-7.

8 Robertson NRC. Management of hyaline membrane disease. Arch Dis Child 1979;54:838-44.

9 Central Statistical Office. Annual abstract of statistics No 95, 1958. London: HMSO, 1959.

10 Central Statistical Office. Annual abstract of statistics No 105, 1968. London: HMSO, 1969.

11 Central Statistical Office. Annual abstract of staristics No 89, 1952. 2nd ed. Nendeln, Liechtenstein: Kraus-Thomson Organization, 1970.

12 Central Statistical Office. Annual abstract of statistics No 115, 1978. London: HMSO, 1979.

13 Central Statistical Office. Annual abstract of statistics No 125, 1988. London: HMSO, 1989

14 Office of Population Censuses and Surveys. Mortality statistics: childhood. Review of the registrar general on deaths in England and Wales, 1984. London: HMSO, 1984. (Series DH3, No 16.)

15 Office of Population Censuses and Surveys. Mortality statistics: perinatal and infant-social and biological factors. Review of the registrar general on death in England and Wales, 1985 . London: HMSO, 1985. (Series DH 3, No 8.)

16 United States Department of Health Education and Welfare Public Health Service. Vital statistics of the United States 1967. Washington, DC: National Center for Health Statistics, 1970.

17 United States Department of Health and Human Services Public Health Service. Vital statistics of the United States, 1977. Hyattsville, Maryland: National Center for Health Statistics, 1980.

18 United States Department of Health and Human Services Public Health
Service. Vital statistics of the United States, 1987. Hyattsville, Maryland: National Center for Health Statistics, 1990.

19 United Nations Department of International and Social Affairs. Handbook of vital statistics systems and methods. Vol II. Review of national practices. New York: United Nations, 1985

20 Kleinbaum DG, Kupper LL, Muller KE. Applied regression analysis and other multivariable methods. 2nd ed. Boston: PWS-Kent Publishing, 1988.

21 Durbin J, Watson GS. Testing for serial correlation in least squares regression. Biometrika 1950;37:409-28.

22 Minitab. Time series. In: Minitab reference manual release 7. State College, Pennsylvania: Minitab, 1989:12.1-8.

23 Kennedy P. A guide to econometrics. Cambridge, Massachusetts: MIT Press, 1985:67-89.

24 Ashton N, Ward B, Serpell G. Role of oxygen in genesis of retrolental fibroplasia: preliminary report. Br f Ophthalmol 1953;37:513-20.

25 The price of perinatal neglect. Lancet 1974;i:437-8.

26 Barrie H. Cost of preventing retrolental fibroplasia. Lancet 1973;ii: 1320.

27 Cohen NM. Cost of preventing retrolental fibroplasia. Lancet 1974;i:747.

28 Silverman WA. The oxygen hypothesis. Retrolental fibroplasia: a modern parable. Toronto: Grune and Stratton, 1980:25-35.

29 Silverman WA. The determinative era of oxygen treatment. Retrolental fibroplasia: a modem parable. Toronto: Grune and Stratton, 1980:59-67.

30 Lewis AF. Cost of preventing retrolental fibroplasia. Lancet 1974;i:746-7.

31 Gross TL, Kazzi GM. Effects of maternal malnutrition and obesity on pregnancy outcome. In: Gleicher N, ed. Principles of medical therapy in pregnancy. New York: Plenum, 1985:332-51.

32 Sternglass EJ. Evidence for low level radiation effects on the human embryo and fetus. In: Sikow MR, Mahlum DD, eds. Proceedings of the ninth annual Hanford biology symposium at Richland, Washington, May 5-8, 1969: annual Hanford biology symposium at Richland, Washington, May S-8, 1969: radiation biology of the fetal and juvenile

33 Lüning G, Scheer J, Schmidt $M$, Ziggel H. Early infant mortality after Chernobyl. Lancet 1989;ii:1081-3.

(Accepted 13 November 1991 )
United Kingdom Trial of Early Detection of Breast Cancer Group Members of the study group are listed at the end of the paper.

\section{Correspondence to:}

Professor J Chamberlain,

Cancer Screening Evaluation

Unit, Institute of Cancer

Research, Section of

Epidemiology, Sutton

SM2 5NG.

\title{
Specificity of screening in United Kingdom trial of early detection of breast cancer
}

\author{
United Kingdom Trial of Early Detection of Breast Cancer Group
}

\section{Abstract}

Objectives-To study the specificity of screening for breast cancer by clinical examination with or without mammography and to estimate the extra breast biopsies resulting from a population screening programme.

Design-Non-randomised, population based study. Setting-Two screening districts (Edinburgh and Guildford) and four comparison districts (Dundee, Oxford, Southmead, and Stoke).

Subjects -49956 women aged $45-64$ in the screening districts and 127109 women in the comparison districts.

Interventions-The screening districts offered women annual screening by clinical examination, with mammography in alternate years for seven years.

Main outcome measures-Numbers of true positive, false positive, true negative, and false negative results; specificity and predictive value of screening; numbers of benign and malignant biopsy specimens.

Results - At their first mammographic and clinical screen 94\% (30 035/31 997) of women without breast cancer were correctly classified as negative; $6 \%$ (1962) were referred for further investigation, but only $321(1 \%)$ required a biopsy to establish that the suspicious lesion was not malignant. At subsequent screens specificity improved to $96 \%$, and only $0.4 \%$ of women without cancer received biopsy. After the first screen the ratio of benign to malignant biopsy specimens was the same as that among women in the comparison centres, but because mammographic screening increased the number of women with both malignant and benign disease referred the number of biopsies was increased up to twofold in the years women were offered screening by mammography.

Conclusion-Our provision of a prompt, highly specialised assessment of women with suspicious lesions at screening may have contributed to the relatively low specificities, while at the same time probably mitigating the adverse effects of low specificity.

\section{Introduction}

One of the main disadvantages of any screening programme is lack of specificity of the screening test because a test that is not specific to the disease in question will give false positive results. A false positive result can cause the patient needless anxiety, inconvenience in having to undergo further diagnostic tests, and possible morbidity if these tests are invasive; it also results in considerable expenditure of personal and health service resources.

In publications about breast cancer screening much emphasis has been given to positivity rates (true and false positive results combined), to the predictive value of a positive test result, and to the ratio of benign to malignant biopsy specimens. ${ }^{14}$ But although these enable specificity to be estimated (especially if knowledge is available about interval cancers, which are a proxy measure for false negative results), there has been little information reported on the probability of a non-diseased woman being correctly classified as negative or, conversely, being needlessly referred for further investigation and sometimes biopsy.

In the United Kingdom trial of early detection of breast cancer two screening centres, Edinburgh and Guildford, invited all women aged 45 to 64 who were registered with a specified number of general practitioners to be screened each year. In years $1,3,5$, and 7 screening was by mammography with clinical examination; in years 2,4 , and 6 it was by clinical examination alone. Four other districts, in which no intervention took place, acted as comparison centres. 